\title{
Enteral Nutrition With an Enteral Formula Containing Egg Yolk Lecithin After Percutaneous Endoscopic Gastrostomy: A Case Series
}

\author{
Tetsuro Akashia, b, Risa Hashimoto ${ }^{\mathrm{a}}$, Akihisa Ohno ${ }^{\mathrm{a}}$, Kazuhide Matsumoto ${ }^{\mathrm{a}}$, \\ Yukari Nakamura ${ }^{a}$
}

\begin{abstract}
The occurrence of diarrhea at the beginning of enteral nutrition complicates the continuation of enteral nutrition. Recently, studies in Japan indicated that diarrhea could be improved by changing the enteral formula to one that is emulsified with egg yolk lecithin. In this study, we administered the enteral formula K-2S plus, which is emulsified with egg yolk lecithin, to 15 patients (four men and 11 women; mean age, $79.9 \pm 2.0$ years) after they had undergone a percutaneous endoscopic gastrostomy (PEG) to prevent the occurrence of diarrhea related to enteral nutrition. Two days after the PEG, the patients would receive $200 \mathrm{~mL} \mathrm{~K}-2 \mathrm{~S}$ plus intermittently three times daily; thereafter, the amount of $\mathrm{K}-2 \mathrm{~S}$ plus was increased according to the patient's condition. The administration rate was scheduled as $200 \mathrm{~mL} / \mathrm{h}$ when $200 \mathrm{~mL}$ were administered at one time. For $\geq 300 \mathrm{~mL}$, the scheduled administration rate was $300 \mathrm{~mL} / \mathrm{h}$. When we administered K-2S plus at the beginning of enteral nutrition after the PEG, the dose of the enteral formula could be increased without any occurrence of diarrhea or vomiting. Five patients had received intravenous nutrition before the PEG; thus, we were concerned about diarrhea in these patients. In conclusion, an enteral formula emulsified with egg yolk lecithin may be safely used at the time of enteral nutrition initiation without causing diarrhea.
\end{abstract}

Keywords: Enteral Nutrition; Diarrhea; Lecithin; Emulsifying agents

\section{Introduction}

Enteral nutrition is the first-choice nutritional therapy for patients without gastrointestinal tract impairments [1]. Diarrhea is a common and serious complication in individuals receiving

Manuscript submitted February 27, 2018, accepted March 19, 2019

aDepartment of Internal Medicine, Saiseikai Fukuoka General Hospital, Fukuoka, Japan

${ }^{b}$ Corresponding Author: Tetsuro Akashi, Department of Internal Medicine, Saiseikai Fukuoka General Hospital, 1-3-46 Tenjin, Chuo-ku, Fukuoka 8100001, Japan. Email: tetsu71jpjp@yahoo.co.jp

doi: https://doi.org/10.14740/gr995w enteral nutrition, with reported incidences ranging from $2 \%$ to $95 \%$, related to differences in patient populations and the diarrhea definitions being used $[2,3]$. Etiological factors, disease severity, and comorbidities (e.g., tube feeding or being admitted to the intensive care unit) can contribute to the onset of diarrhea in critically ill patients [4]. Once established, diarrhea can lead to dehydration, electrolyte loss, and malnutrition, which further impair the patient's health and may necessitate other clinical interventions, resulting in a longer hospital stay and increased cost [5].

Lipids in formulas can cause diarrhea, and formulas with a high fat content have been associated with osmotic diarrhea in patients with burns $[6,7]$. Enteral formulas are emulsified to improve lipid absorption. In commercially available enteral formulas, egg yolk lecithin, soybean lecithin, or synthetic compounds are used as emulsifiers. Emulsification with egg yolk lecithin is superior for lipid absorption as the emulsion is not easily broken, even under low $\mathrm{pH}$ conditions [8]. The effect of egg yolk lecithin emulsion on the suppression of diarrhea during enteral nutrition has been studied in clinical cases and rat models [8]. Enteral formulas emulsified with egg yolk lecithin are considered to promote lipid absorption by preventing the destruction of emulsified substances by gastric acid.

In this study, we administered the enteral formula $\mathrm{K}-2 \mathrm{~S}$ plus (JANEF K-2S plus; Kewpie Corporation, Tokyo, Japan) that is emulsified with egg yolk lecithin and will be on sale in Japan starting in 2018. K-2S plus was given to patients who were hospitalized for percutaneous endoscopic gastrostomy (PEG) between January and November 2017 to evaluate whether enteral nutrition with this formula could be continued without the occurrence of diarrhea.

\section{Case Reports}

\section{Ethics statement}

The ethics committee of the Saiseikai Fukuoka General Hospital (no. 2016-11-4, November 18, 2016) approved the study protocol. All clinical investigations were conducted according to the principles expressed in the Declaration of Helsinki. The study was conducted after written informed consent was ob- 
Table 1. Composition of K-2S Plus

\begin{tabular}{|c|c|}
\hline Nutrient & Units/100 mL \\
\hline Energy, kcal & 100 \\
\hline Protein, $g$ & 3.5 \\
\hline Fat, g & 3.3 \\
\hline Carbohydrates, $g$ & 14.1 \\
\hline Dietary fiber, $g$ & 0 \\
\hline Sodium, mg & 120 \\
\hline Potassium, mg & 60 \\
\hline Chloride, $\mathrm{mg}$ & 60 \\
\hline Calcium, mg & 60 \\
\hline Magnesium, mg & 13 \\
\hline Phosphorous, mg & 45 \\
\hline Iron, mg & 1.2 \\
\hline Zinc, mg & 1 \\
\hline Copper, mg & 0.07 \\
\hline Iodine, $\mu \mathrm{g}$ & 0 \\
\hline Sulfur, g & 0.03 \\
\hline Selenium, $\mu \mathrm{g}$ & 5 \\
\hline Molybdenum, $\mu \mathrm{g}$ & 3 \\
\hline Vitamin $\mathrm{A}, \mu \mathrm{g}$ retinol equivalents & 85 \\
\hline Vitamin D, $\mu \mathrm{g}$ & 0.6 \\
\hline Vitamin E, mg & 1.2 \\
\hline Vitamin $\mathrm{K}, \mu \mathrm{g}$ & 9 \\
\hline Thiamin, mg & 0.13 \\
\hline Riboflavin, mg & 0.15 \\
\hline Niacin, mg & 2.8 \\
\hline Vitamin B-6, mg & 0.25 \\
\hline Vitamin B-12, $\mu \mathrm{g}$ & 0.4 \\
\hline Folic acid, $\mu \mathrm{g}$ & 25 \\
\hline Pantothenic acid, mg & 1 \\
\hline Biotin, $\mu \mathrm{g}$ & 5 \\
\hline Vitamin $C, m g$ & 20 \\
\hline
\end{tabular}

tained from all study participants or their legal representatives.

\section{Patients}

We evaluated 15 patients (four men and 11 women; mean age, $79.9 \pm 2.0$ years) who were hospitalized to undergo a PEG between January and November 2017 due to cerebrovascular disorders $(\mathrm{n}=6)$, dementia $(\mathrm{n}=6)$, and neurodegenerative diseases $(n=3)$. Before the PEG, the routes of nutrition administration in these patients were nasoenteric feeding $(\mathrm{n}=$ 9 ), intravenous nutrition $(n=5)$, and oral nutrition $(n=1)$. The subjects' mean body mass index (BMI) before the PEG was $18.2 \pm 4.0 \mathrm{~kg} / \mathrm{m}^{2}$ (range, $10.3-24.3 \mathrm{~kg} / \mathrm{m}^{2}$ ), and their mean al- bumin concentration was $2.6 \pm 0.4 \mathrm{~g} / \mathrm{dL}$ (range, $1.5-3.3 \mathrm{~g} / \mathrm{dL}$ ).

\section{Enteral feeding}

The patients underwent PEG using the introducer technique with a 20 Fr catheter kit (Intolief PEG kit, Create Medic Co., Ltd, Yokohama, Japan). The enteral formula was administered intermittently three times daily. Administration of a glutamine preparation $(10 \mathrm{~g} \mathrm{~L}$-glutamine and $5 \mathrm{~g}$ water-soluble dietary fiber) was started on the day after the PEG, and the enteral formula (K-2S plus, $200 \mathrm{~mL}$ ) was administered after the patients had received three doses of the glutamine preparation (i.e., 2 days after the PEG). Thereafter, the amount of K-2S plus was increased according to the patient's condition. The final enteral formulas dosages were $1,100 \mathrm{~mL} /$ day in two cases and 1,200 $\mathrm{mL} /$ day in 13 cases.

The scheduled administration rate was $200 \mathrm{~mL} / \mathrm{h}$ when $200 \mathrm{~mL}$ was administered at one time. For $\geq 300 \mathrm{~mL}$, the scheduled administration rate was $300 \mathrm{~mL} / \mathrm{h}$.

The composition of K-2S plus is shown in Table 1. In summary, K-2S plus has an osmotic pressure of $340 \mathrm{mOsm} / \mathrm{L}$ and a caloric density of $1 \mathrm{kcal} / \mathrm{mL}$; it contains egg yolk lecithin as the emulsifier. The formula's energy distribution (units/100 $\mathrm{mL}$ ) is $3.5 \mathrm{~g}$ protein, $3.3 \mathrm{~g}$ fat, $14.1 \mathrm{~g}$ carbohydrates, and $0 \mathrm{~g}$ dietary fiber; its fat composition is $40 \%$ saturated fatty acids, $40 \%$ monounsaturated fatty acids, and $20 \%$ polyunsaturated fatty acids.

\section{Clinical course}

The mean observation period from the start of the administration of the enteral formula was $5.5 \pm 0.4$ days (range, $4-10$ days). After increasing the formula dosage to the previous or the minimum required amount of enteral nutrition, the patients were transferred to the hospital at which they had previously been hospitalized. The final dosage of the enteral formula was reached 3 days after the start of enteral formula administration in all cases.

\section{Complications and deviations from the administration sched- ule}

Table 2 lists the complications related to enteral feeding and the deviations from the administration schedule. Gastrointestinal complications were defined as follows: vomiting was defined by vomiting a fluid diet once and diarrhea was defined as the occurrence of watery stools $\geq$ three times/day.

We did not observe any vomiting or diarrhea, and enteral nutrition could be continued in all cases. In one patient, the stomach contents leaked from a fistula that was related to the PEG. In this case, the enteral formula was changed to a semisolid enteral formula after K-2S plus reached the final dose. After this change, the peristomal leakage improved, and the semisolid enteral nutrition could be administered without interruption. 
Table 2. Events Related to Enteral Nutrition With K-2S Plus After Percutaneous Endoscopic Gastrostomy

\begin{tabular}{|l|l}
\hline & N \\
\hline Complications & 0 \\
Vomiting & 0 \\
\hline Diarrhea & 1 \\
Peristomal leakage & 2 \\
Deviations from the administration schedule & \\
\hline Initiation with a slower administration rate or deceleration of the administration rate & \\
\hline
\end{tabular}

In 13 of the 15 patients, $\mathrm{K}-2 \mathrm{~S}$ plus could be administered following the scheduled administration rate. In one case of enteral nutrition after intravenous nutrition, the initial administration rate was $100 \mathrm{~mL} / \mathrm{h}$. In the other case, an increase in the number of (non-watery) stools/day was observed when the $\mathrm{K}-2 \mathrm{~S}$ plus dose was increased to $300 \mathrm{~mL}$; therefore, the formula dosage was scaled back to $200 \mathrm{~mL} / \mathrm{h}$ without increasing the administration rate.

\section{Discussion}

The occurrence of diarrhea related to enteral nutrition makes the continuation of enteral nutrition difficult, and careful management of the diarrhea is required. When administering an enteral formula, not only the administration method (e.g., the administration rate) but also the choice of formula is important to be able to continue enteral nutrition and avoid related complications. In this case series, we used an enteral formula containing egg yolk lecithin as the emulsifier; we show that the dosage of the enteral formula could be increased without any instances of diarrhea. A randomized controlled trial (RCT) of critically ill neurological patients compared a formula based on real foods to a conventional formula and showed that the mean duration of watery stools occurring $>$ three times/day was 0.8 and 2.0 days for the former and latter formula, respectively [9]. Moreover, a previous report at our institution showed that diarrhea occurred in two of 29 patients $(6.9 \%)$ using K-LEC combined with the pectin gel REF-P1 (Kewpie Corporation, Tokyo, Japan) after a PEG [10]. Therefore, the results of this study seem to be comparable to those reported previously.

Some recent reports in Japan indicated that diarrhea could be improved (in some cases, immediately) by changing the type of enteral formula to K-2S (JANEF K-2S; Kewpie Corporation) or K-LEC (JANEF K-LEC; Kewpie Corporation) [11-13]. In vitro experiments showed that an egg yolk lecithin emulsion was stable after the addition of artificial gastric juice, which may have contributed to improved fat absorption in rats with bile duct ligation who received egg yolk lecithin [8]. Akashi and colleagues hypothesized that the emulsification of the enteral formula with egg yolk lecithin promoted lipid absorption by preventing the destruction of the emulsified substances by gastric acid [8]. In clinical cases and a rat model with short bowel syndrome, switching from a formula emulsified with synthetic compounds to K-LEC, which is emulsified with egg yolk lecithin, was associated with improvements in diarrhea [8].

Dysbiosis might explain how improved lipid absorption through an emulsifier is related to improving diarrhea. Chronic diarrhea can be caused by intestinal bacterial disturbances such as small intestinal bacterial overgrowth (SIBO) [14]. Fat malabsorption may result from SIBO because of the bacterial deconjugation of bile acids and subsequent deficiency of intraluminal conjugated bile acids [15]. Many clinical conditions, including parenteral nutrition, diabetes mellitus, drug-induced inhibition of acid secretion, and irritable bowel syndrome, as well as old age are associated with SIBO [16, 17]. SIBO also frequently occurs in patients receiving enteral nutrition, in which it may cause excess lipid accumulation.

$\mathrm{K}-2 \mathrm{~S}$ plus is a modified enteral formula, based on the composition of K-LEC, to comply with the Dietary Reference Intakes for Japanese (2015) by the Ministry of Health, Labor and Welfare; this formula will be on sale starting in 2018. In this study, we used K-2S plus to initiate enteral nutrition after a PEG. Of 15 cases, five received intravenous nutrition before the PEG. As in these patients the gastrointestinal tract had not been used before the PEG, the potential of diarrhea emergence was a concern. In our study, enteral nutrition with K-2S plus could be used without causing diarrhea in all patients. The administration rate was consistently moderately high at $200-300$ $\mathrm{mL} / \mathrm{h}$.

This case series has some limitations. First, it was a shortterm observation of only few cases. Second, we did not include any controls (patients not receiving $\mathrm{K}-2 \mathrm{~S}$ plus) due to the study design. A future RCT with a longer observation period is necessary to overcome these limitations.

Despite these limitations, our findings indicate that K-2S plus emulsified with egg yolk lecithin can be safely used without causing diarrhea at the time of enteral nutrition initiation.

\section{Acknowledgments}

We thank the staff of the Saiseikai Fukuoka General Hospital for excellent patient care. We also thank Editage (www.editage.jp) for English language editing.

\section{Grant Support}

This study was supported in part by a grant received from the 
Kewpie Corporation (Tokyo, Japan).

\section{Financial Disclosure}

Tetsuro Akashi received funds for this research and lecture fees from the Kewpie Corporation. The other authors declare that they have no competing interests.

\section{References}

1. Aspen Board of Directors, the Clinical Guidelines Task F. Guidelines for the use of parenteral and enteral nutrition in adult and pediatric patients. JPEN J Parenter Enteral Nutr. 2002;26(1 Suppl):1SA-138SA.

2. Whelan K. Enteral-tube-feeding diarrhoea: manipulating the colonic microbiota with probiotics and prebiotics. Proc Nutr Soc. 2007;66(3):299-306.

3. Whelan K, Schneider SM. Mechanisms, prevention, and management of diarrhea in enteral nutrition. Curr Opin Gastroenterol. 2011;27(2):152-159.

4. Thorson MA, Bliss DZ, Savik K. Re-examination of risk factors for non-Clostridium difficile-associated diarrhoea in hospitalized patients. J Adv Nurs. 2008;62(3):354-364.

5. Kyne L, Hamel MB, Polavaram R, Kelly CP. Health care costs and mortality associated with nosocomial diarrhea due to Clostridium difficile. Clin Infect Dis. 2002;34(3):346-353.

6. Viall C, Porcelli K, Teran JC, Varma RN, Steffee WP. A double-blind clinical trial comparing the gastrointestinal side effects of two enteral feeding formulas. JPEN J Parenter Enteral Nutr. 1990;14(3):265-269.

7. Gottschlich MM, Warden GD, Michel M, Havens P, Kopcha R, Jenkins M, Alexander JW. Diarrhea in tubefed burn patients: incidence, etiology, nutritional impact, and prevention. JPEN J Parenter Enteral Nutr. 1988;12(4):338-345.

8. Akashi T, Muto A, Takahashi Y, Nishiyama H. Enteral formula containing egg yolk lecithin improves diarrhea.
J Oleo Sci. 2017;66(9):1017-1027.

9. Schmidt SB, Kulig W, Winter R, Vasold AS, Knoll AE, Rollnik JD. The effect of a natural food based tube feeding in minimizing diarrhea in critically ill neurological patients. Clin Nutr. 2018.

10. Akashi T, Takamatsu Y, Takaoka T, Nozaki A, Tanaka T, Shimizu J, Yamada M, et al. Efficacy of the introduction of enteral nutrition combined with a pectin gel of REFP1 after percutaneous endoscopic gastrostomy. J Jap Soc Parenter Enter Nutr. 2016;32:878-881. (in Japanese).

11. Matsumura A, Yamamoto T, Sakurama T, Tani K, Uno K, Yamada S, Hashimoto R, et al. NST efforts on improvement of diarrhea-dumping symptoms in tube feeding. J Metabol Clin Nutr. 2007;10:572. (in Japanese).

12. Akashi T, Takahashi S, Tomari M, Koikawa N, Nakamura M, Ishii T, Sako Y. Intractable diarrhea of severe pneumonia patient it was improved by changing the enteral nutritional formula to the JANEF K-2S: a case report. J Metabol Clin Nutr. 2011;14:33-38. (in Japanese).

13. Akashi T, Takahashi S, Esaki M, Ikeda H, Yamada M, Tachibana Y, Mukai K, et al. Effect of enteral formula containing egg yolk lecithin to prolonged diarrhea after the treatment of Clostridium difficile associated disease: Case Reports. J Metabol Clin Nutr. 2013;16:331-337. (in Japanese).

14. Fan X, Sellin JH. Review article: Small intestinal bacterial overgrowth, bile acid malabsorption and gluten intolerance as possible causes of chronic watery diarrhoea. Aliment Pharmacol Ther. 2009;29(10):1069-1077.

15. Kim YS, Spritz N, Blum M, Terz J, Sherlock P. The role of altered bile acid metabolism in the steatorrhea of experimental blind loop. J Clin Invest. 1966;45(6):956-962.

16. Grace E, Shaw C, Whelan K, Andreyev HJ. Review article: small intestinal bacterial overgrowth - prevalence, clinical features, current and developing diagnostic tests, and treatment. Aliment Pharmacol Ther. 2013;38(7):674-688.

17. Almeida JA, Kim R, Stoita A, McIver CJ, Kurtovic J, Riordan SM. Lactose malabsorption in the elderly: role of small intestinal bacterial overgrowth. Scand J Gastroenterol. 2008;43(2):146-154. 